\title{
Material characterization of a novel new armour steel
}

\author{
J.N. Bester ${ }^{\mathrm{a}}$ and W.E. Stumpf \\ Department of Materials Science and Metallurgical Engineering, University of Pretoria, South Africa
}

\begin{abstract}
The material characterization of a novel new armour steel with comparison to a leading commercial benchmark alloy is presented. Direct ballistic and experimental comparison is drawn. The $5.56 \times 45 \mathrm{~mm}$ [M193] and $7.62 \times 51 \mathrm{~mm}$ [NATO Ball] projectiles were used in a cartridge type high pressure barrel configuration to evaluate the superior plugging resistance of the new steel over a range of plate thicknesses. To characterize the dynamic plasticity of the materials, quasi-static, notched and high temperature tensile tests as well as Split Hopkinson Pressure Bar tests in tension and compression were performed. The open source explicit solver, IMPACT (sourceforge.net) is used in an ongoing numerical and sensitivity analysis of ballistic impact. A simultaneous multi variable fitting algorithm is planned to evaluate several selected numerical material models and show their relative correlation to experimental data. This study as well as micro-metallurgical investigation of adiabatic shear bands and localized deformation zones should result in new insights in to the underlying metallurgical and physical behavior of armour plate steels during ballistic perforation.
\end{abstract}

\section{Introduction}

This paper forms part of an ongoing investigation into the armour material design and optimization for level 1 kinetic energy threat [1]. The $5.56 \times 45 \mathrm{~mm} \mathrm{M} 193$ projectile is the limiting caliber for this level and the typical target perforation mechanism is plugging (figure 1) with adiabatic shear bands as well as intergranular cracks (figure 2). At present commercial armour plate data sheets only focus on the following mechanical properties; hardness, yield strength, tensile strength, minimum elongation and low temperature impact toughness. The hardness of the material is often included in the commercial product name and seems to be the only required mechanical property distinguishing ballistic resistant plate from structural steel. Hardness is an indicator of tensile strength and as extensive analytical work [2-5] relies almost entirely on the tensile strength of the material, the use of material hardness as a ballistic performance indicator is entirely valid in certain cases. Recent work [6] indicates, however that material hardness alone might not be the only required mechanical property for optimal ballistic performance. The development of Dual-Phase, TRIP and especially TWIP alloys [7] (with tensile strength of $\approx 1700 \mathrm{MPa}$ at $45 \%$ strain), indicates that enhanced plastic energy absorption could be attained with higher work-hardening rates. Thermal softening delays, dynamic plasticy damage and phase transformations should also be included in the development of optimal ballistic performance. The new experimental alloy was developed as part of a group of alloys, aimed at providing superior ballistic resistance for small-arms projectiles at lower plate thickness levels, primarily for use in light armoured vehicles. The chemical composition of the alloys was based on high manganese content, as well as moderate levels of chromium, nickel and molybdenum. In the as-rolled condition, the plate produced to these alloy formulations produced a predominantly martensitic microstructure, with some retained austenite evident. Alloy 1 was the alloy in the group aimed at the semi-structural

a e-mail: jacques. bester@megchem.co . za
$500 \mathrm{HB}$ application, where the armour plate is fabricated into the vehicle chassis and where the $7-8 \mathrm{~mm}$ armour plate would provides adequate resistance to the NATO STANAG 4569 Level 1 ballistic threat [1]. This experimental ballistic resistive material Alloy1 [8], a tempered variant Alloy1 T200 and a leading commercial ballistic benchmark material have been tested. The normal tensile tests, high temperature tensile tests, notched tensile tests and high strain-rate SHPB tests results are summarized with the ballistic test procedure and results discussed in detail.

\section{Ballistic performance test procedure and results}

\subsection{Test equipment and procedure}

A high pressure ballistic test barrel (figure 3) with standard cartridge charge was used in this investigation. Each cartidge is loaded before the shot to control the impact velocity, however the range of impact velocity for a single charge can be as high as $50 \mathrm{~m} / \mathrm{s}$ (figure 4). The ballistic test procedure and evaluation rules defined in [9] were used as the starting point and only slight deviations are allowed to reduce cost and testing time. A standard witness system consisting of a $0.5 \mathrm{~mm}$ aluminium plate positioned $150 \mathrm{~mm}$ from the back face of the test plate would typically be used. This witness plate should extend over a large enough area to detect all of the projectiles and fragments. Characterization of impact events near the ballistic limit of the material is defined as partial penetration if light is not observed to pass through the witness plate or complete penetration if the light passes through the witness plate. For this investigation a simplified and more conservative approach was followed by visual inspection of the test plate's back face. An impact event above the ballistic limit results in a clear hole through the plate and is classified a complete perforation or CP. With the impact velocity well below the ballistic limit almost no damage is observed on 


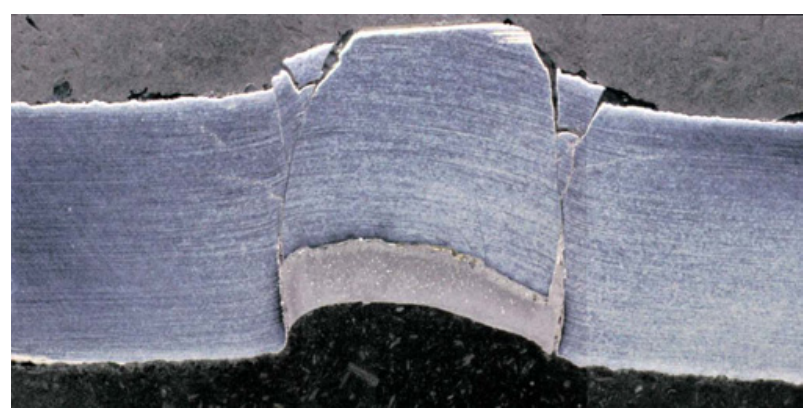

Fig. 1. Micrograph of ballistic plug formation and partial expulsion on the newly developed armour steel $(5.56 \times 45 \mathrm{~mm}$ on $7.5 \mathrm{~mm}$ plate).

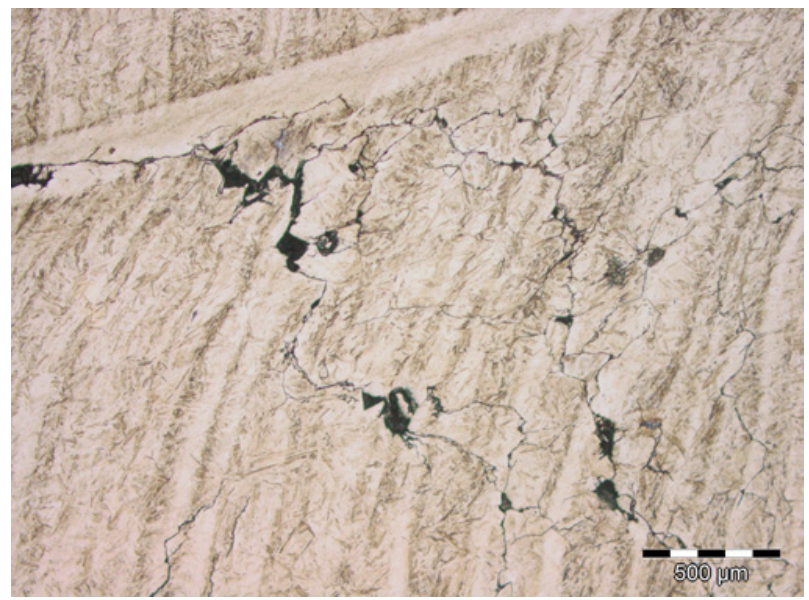

Fig. 2. High magnification of micrograph in figure 1 (area close to partial plug formation).

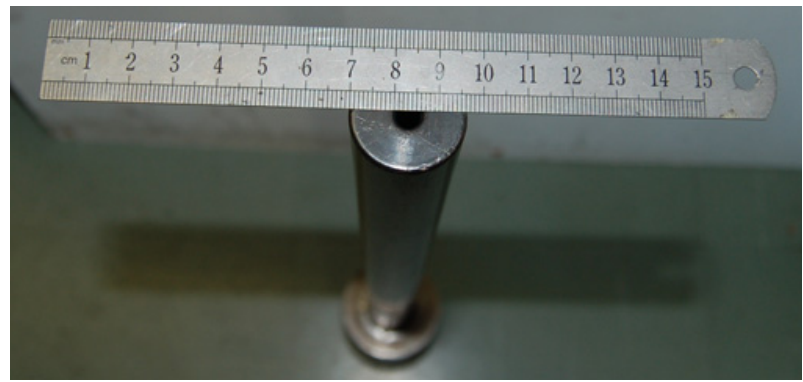

Fig. 3. High pressure ballistic test barrel.

the back face of the test plate with only slight bulging in some instances. These types of impacts are classified as non-perforation or NP. Impact events near the ballistic limit of the plate result in partial perforations or PP as seen in figure 5. Circumferential cracks with an inclosed angle larger than $180^{\circ}$ are classified as complete perforations. The following procedure was followed for every test plate. Firstly a few shots are used to establish a test range with at least one $\mathrm{CP}$ and one NP. Once the test range is known, the charge is varied only slightly to influence the impact velocity. The aim of this section of the test is to vary the impact velocity required by the test plate such that half of the shots result in NP and the other half in CP. All shots should also have in impact velocity within $40 \mathrm{~m} / \mathrm{s}$ of each other. This process has proved to

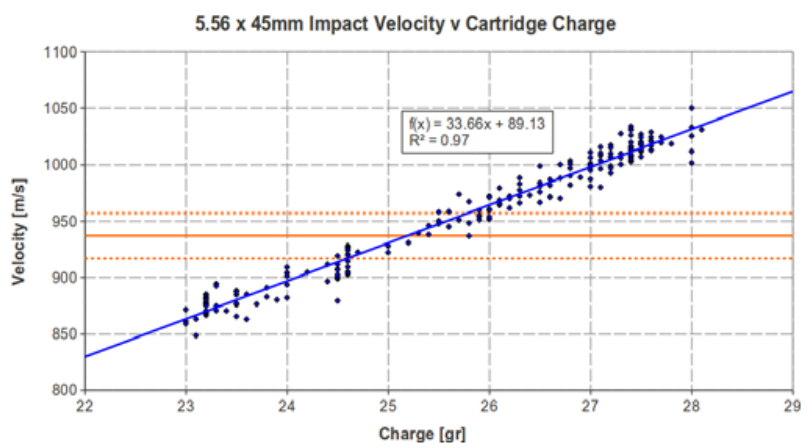

Fig. 4. Impact velocity range of cartridge type high pressure ballistic test barrel configuration.

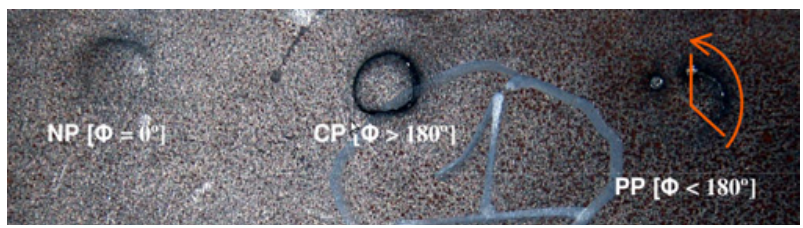

Fig. 5. Classification of partial perforation for impacts near the ballistic limit of the material.

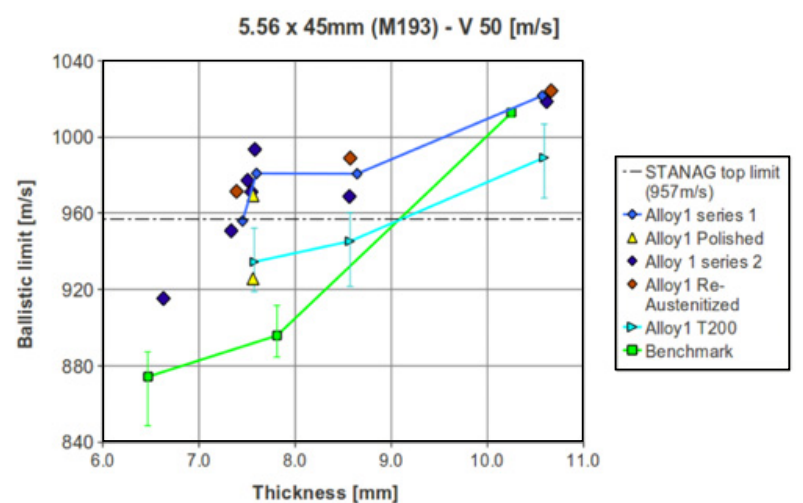

Fig. 6. Ballistic performance of Alloy1, Alloy1 T200 and the Benchmark material against $5.56 \times 45 \mathrm{~mm}(\mathrm{M} 193)$ projectile at $10 \mathrm{~m}$.

be challenging for some tests and a reduced number of shots had to be used to calculate the V50 ballistic limit (50\% probability of perforation) value. During the test the following values were recorded, Shot number (also marked on the plate.), Cartridge charge [grain], Muzzle velocity $[\mathrm{m} / \mathrm{s}]$ and Impact result [CP, PP or NP]. After the test all PP impact events are closely examined to verify if any fragments were ejected. Impact events with fragments are re-classified as $\mathrm{CP}$ and impact events without fragments as NP. The muzzle velocity is adjusted to the impact velocity value by subtracting velocity drop over $13.5 \mathrm{~m}\left(1.23 \frac{\mathrm{m} / \mathrm{s}}{\mathrm{m}}\right.$ for $5.56 \times 45 \mathrm{~mm})$. The average is calculated using an equal number of $\mathrm{CP}$ and NP events with the fastest NP values and slowest $\mathrm{CP}$ values included.

\subsection{Ballistic results for $5.56 \times 45 \mathrm{~mm}(\mathrm{M} 193)$ projectile}

A total number of 22 plates were tested with the $5.56 \times$ $45 \mathrm{~mm}$ M193 caliber round. The results are presented in figure 6 with the upper STANAG limit (Table 1) in dotted 
Table 1. Kinetic energy threat classification [1].

\begin{tabular}{|c|c|c|c|}
\hline \multirow{2}{*}{ Level } & \multicolumn{3}{|c}{ KE Threat } \\
\cline { 2 - 4 } & Ammunitions & $\begin{array}{l}\text { Supplier } / \text { Specific test } \\
\text { ammunitions }\end{array}$ & $\begin{array}{c}\text { V proof [m/s] } \\
\{ \pm 20 \mathrm{~m} / \mathrm{s}\}\end{array}$ \\
\hline \multirow{4}{*}{1} & $7.62 \mathrm{~mm} \times 51$ NATO ball & $\begin{array}{l}\text { Ball M80, copper jacket, 9.65 g lead } \\
\text { core or C21, } 9.5 \mathrm{~g}, \mathrm{DM} 41 \text { with tomac } \\
\text { jacket and lead core, projectile } \\
\text { weight: } 9.45 \mathrm{~g}\end{array}$ & 833 \\
\cline { 2 - 4 } & $5.56 \mathrm{~mm} \times 45$ NATO SS109 & $\begin{array}{l}\text { SS109, } 4.0 \mathrm{~g}, \text { M855, DM11, tomac } \\
\text { jacket, steel and lead core, projectile } \\
\text { weigth: } 4 \mathrm{~g}\end{array}$ & 900 \\
\cline { 2 - 4 } & $5.56 \mathrm{~mm} \times 45 \mathrm{M} 193$ & M 193, Ball $3.56 \mathrm{~g}$ & 937 \\
\hline
\end{tabular}

Table 2. Summary of ballistic results for $5.56 \times 45 \mathrm{~mm}$ (M193) projectile.

\begin{tabular}{|c|c|c|c|c|c|}
\hline Plate no. & Thickness [mm] & V50 [m/s] & + & - & No. Shots \\
\hline TFL 1/3 [2210124] TP1 & 7.454 & 955.96 & 17.93 & 17.91 & 18 \\
\hline TFL 3/1 [2210124] TP2 & 7.599 & 980.88 & 14.21 & 9.74 & 10 \\
\hline TFL 5/1 [2208934] TP3 & 8.647 & 980.72 & 19.97 & 15.88 & 18 \\
\hline TFL 3/2 [2210125] TP4 & 10.574 & 1021.62 & 6.72 & 19.21 & 10 \\
\hline Alloy \#1 T SM12 TP22 & 7.577 & 934.50 & 17.70 & 1557 & 22 \\
\hline Alloy \#1 T SM10 TP25 & 8.574 & 945.33 & 15.01 & 23.59 & 22 \\
\hline Alloy \#1 T SM1 TP26 & 10.595 & 989.17 & 17.62 & 21.14 & 20 \\
\hline Alloy \#1 SM12 TP33 & 6.631 & 915.33 & 15.48 & 20.53 & 18 \\
\hline Alloy \#1 SM11 TP39 & 7.336 & 950.83 & 22.28 & 17.67 & 16 \\
\hline Alloy \#1 SM15 TP29 & 7.546 & 971.24 & 18.66 & 9.84 & 18 \\
\hline Alloy\#1 SM12 TP30 & 7.582 & 993.49 & 18.11 & 9.09 & 20 \\
\hline Alloy \#1 SM13 TP31 & 7.507 & 977.26 & 15.34 & 21.00 & 20 \\
\hline Alloy \#1 SM7 TP40 & 8.567 & 968.82 & 22.58 & 14.92 & 20 \\
\hline Alloy \#1 SM3 TP32 & 10.620 & 1018.58 & 18.51 & 17.59 & 18 \\
\hline Alloy \#1 RA900 SM12 TP34 & 7.392 & 971.46 & 11.34 & 9.97 & 18 \\
\hline Alloy \#1 RA900 SM7 TP35 & 8.575 & 988.92 & 21.58 & 13.26 & 22 \\
\hline Alloy \#1 RA900 SM3 TP36 & 10.667 & 1024.19 & 18.41 & 14.29 & 24 \\
\hline SM12 TP37 Back Polished & 7.563 & 969.57 & 14.82 & 18.12 & 12 \\
\hline SM12 TP37 Front Polished & 7.563 & 925.70 & 13.35 & 14.41 & 6 \\
\hline Benchmark TP16 & 6.468 & 874.27 & 13.04 & 25.75 & 22 \\
\hline Benchmark PT12 & 7.813 & 895.86 & 15.79 & 11.23 & 12 \\
\hline Benchmark PT13 & 10.253 & 1012.66 & 2.24 & 2.26 & 8 \\
\hline
\end{tabular}

lines and listed in Table 2. The data range bars have been removed from Alloy1 data points to clarify the result in figure 6. Alloy 1 is positioned above both the benchmark and Alloy 1 T200. The top limit of $937+20=957 \mathrm{~m} / \mathrm{s}$ for $5.56 \times 45 \mathrm{~mm}(\mathrm{M} 193)$ projectile at $10 \mathrm{~m} \mathrm{[1]} \mathrm{is} \mathrm{shown}$ by the dotted line which can be used to determine the minimum required thickness to defeat the $5.56 \times 45 \mathrm{~mm}$ (M193) projectile. A plate thickness of $9 \mathrm{~mm}$ is required by both the benchmark and Alloy1 T200 materials with only $7.3 \mathrm{~mm}$ (lower bound value) required by Alloy1. Series 2 of Alloy 1 show the variance between different plates from the same cast and heat treatment. The re-austenitized plates proved that no substantial auto-tempering should be allowed after the final rolling of the plates as ballistic preformance was similar to series 1 of Alloy1. One curious result is the ballistic performance effect of a polished (surface ground by hand with soft abrasive) surface finish in the front side of the plate (Yellow triangles). A reduction in ballistic limit of $44 \mathrm{~m} / \mathrm{s}$ is seen with the front face polished compared to the back face. The ballistic limit of the plate with the back face polished is similar to plates without any polished faces.

\section{Split Hopkinson pressure bar results}

Elastic stress waves measured in the pressure bars are related to force and displacement values within to the specimen as shown in the next section. The dynamic plasticity response of the material is then calculated $[10,11]$.

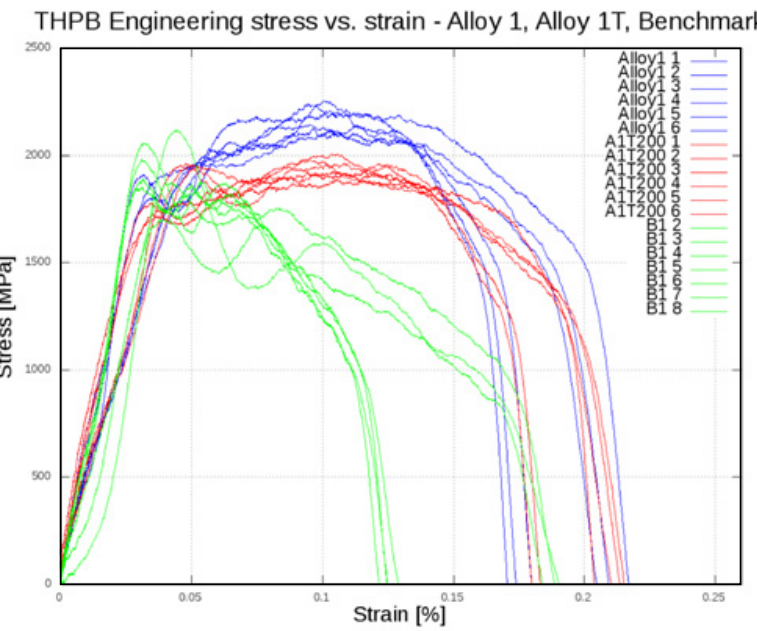

Fig. 7. THPB Stress Result Summary of Alloy1, Alloy1 T200 and the Benchmark alloy.

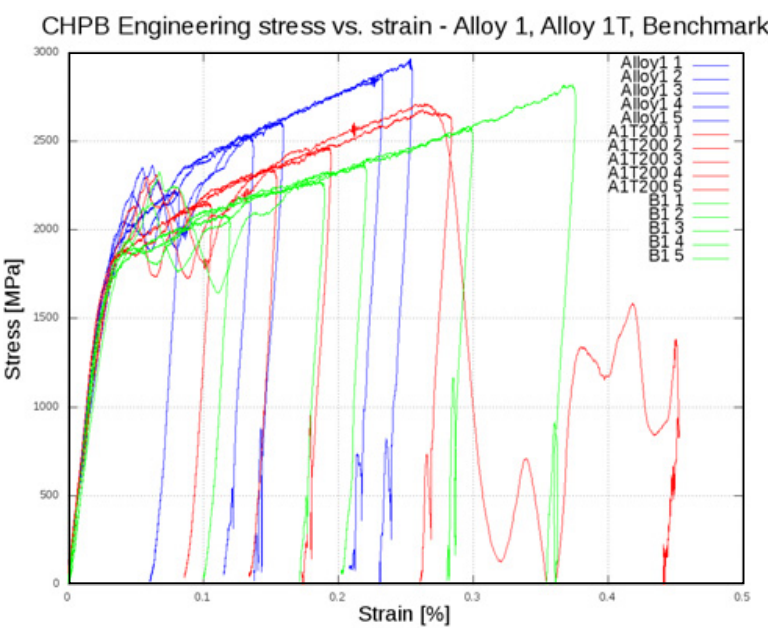

Fig. 8. CHPB Stress Result Summary of Alloy1, Alloy1 T200 and the Benchmark alloy.

\subsection{Tensile results}

The energy absorption capacity in tension, as well as an apparent delay in localized deformation of the experimental Alloy1 when compared to the benchmark alloy, seems higher within the strain-rate range of 500-1200 $\frac{1}{s}$.

\subsection{Compression results}

A clear trend is seen in figure 8 with Alloy1 above Alloy1 T200 and the benchmark material below both. The energy absorption capacity in compression, as well as the workhardening rate of the experimental Alloy1 seems higher within the strain-rate range of 300-1000 $\frac{1}{s}$.

\section{Conventional tensile tests}

Some of the completed tensile test results are reported in this section for direct comparison of the materials. 
Table 3. Conventional tensile result summary from 35 tenisle tests of Alloy1.

\begin{tabular}{|c|c|c|}
\hline Value & UTS [MPa] & Elongation [\%] \\
\hline \hline Minimum & 1954.59 & 4.06 \\
\hline Maximum & 2416.40 & 17.77 \\
\hline Mean & 2104.95 & 13.58 \\
\hline Stdev. & 72.13 & 3.20 \\
\hline
\end{tabular}

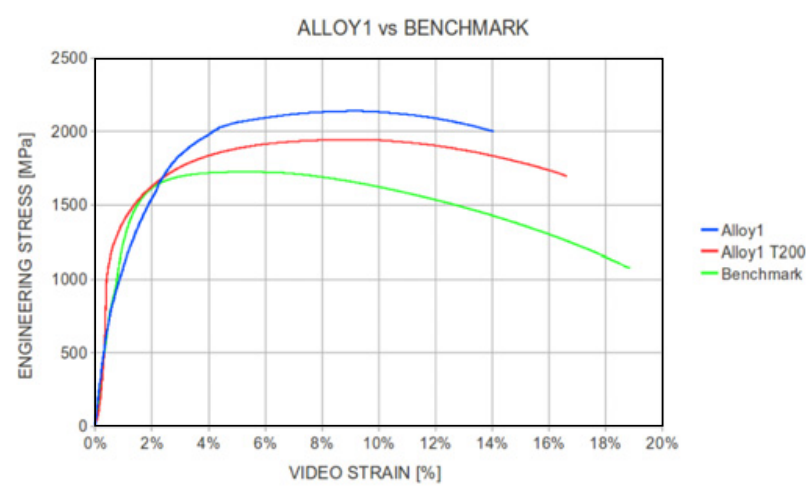

Fig. 9. Conventional tensile result comparison for Alloy1, Alloy1 T200 and the Benchmark alloy.

\subsection{Normal tensile tests}

A number of standard tensile tests were performed on Alloy1 using EDM profiled and face ground specimens, yielding geometric accuracy of $0.010 \mathrm{~mm}$ on the width and $0.050 \mathrm{~mm}$ on the thickness. The results are summarized in the table 3. A comparison of the standard tensile behavior, tested on a machine with video extensometer, of Alloy1, Alloy1 T200 and the Benchmark alloy is shown in figure 9. The energy absorption capacity of the materials is not evident but nevertheless, direct comparison shows the experimental Alloy1 has a higher tensile strength with Alloy1 T200 lower and the benchmark material the lowest. The delay in localized deformation for Alloy 1 is also evident.

\subsection{Notch tensile tests}

Some of the notched tensile specimens were tested without the video extensometer and the direct comparison with therefore is not possible at this stage. Only results for the Alloy1 T200 and benchmark materials are therefore shown. The stress triaxiality effect on the fracture strain can be compared using the video strain in figure 10. Alloy 1 T200 failed at lower strain for each of the notch factors and is clearly more severely affected by triaxiality than the benchmark material.

\subsection{High temperature tests}

Only Alloy 1 and the benchmark steel were tested at elevated temperatures as heating of the specimen past $200^{\circ} \mathrm{C}$ would negate any prior tempering effects. The comparative results in figure 11 show a clear delay in thermal softening of Alloy 1 up to $500^{\circ} \mathrm{C}$ if compared to the benchmark alloy. After this point the tensile strength of the two materials converge.

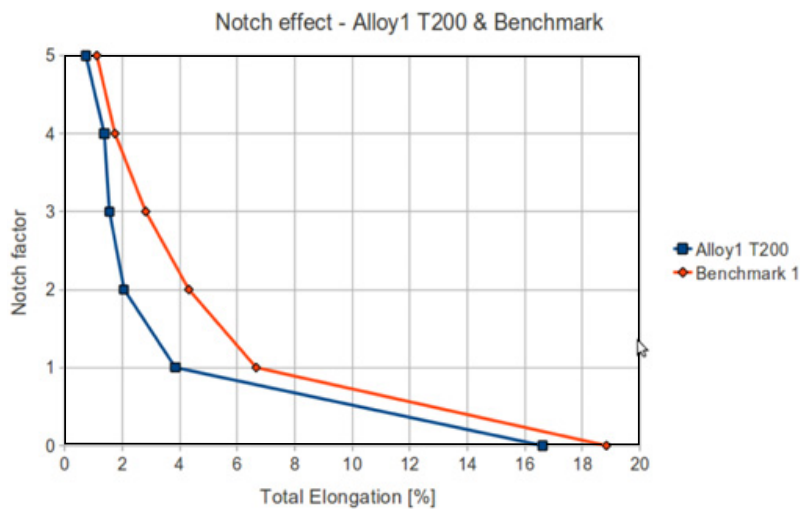

Fig. 10. Comparison of the notch effect on Alloy1 and the Benchmark alloy.

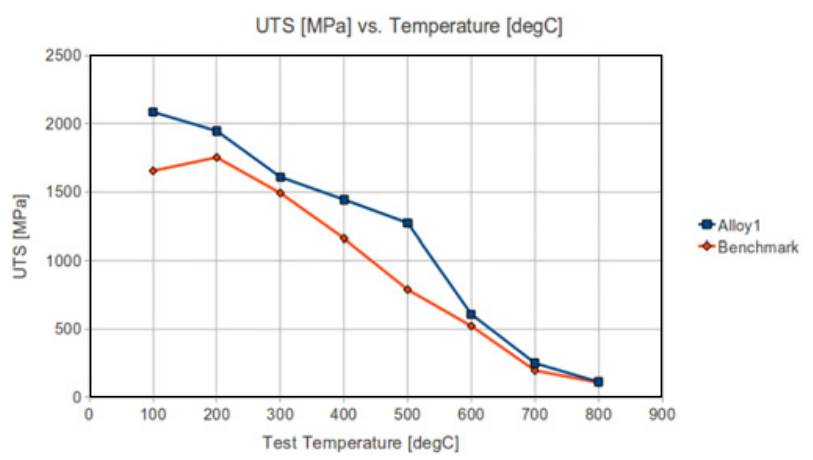

Fig. 11. High temperature tensile result for the Alloy1 and Benchmark materials.

\section{Summary and conclusions}

Some results on an experimental, ballistic and numerical characterization of a novel new armour steel with comparison to a current commercial benchmark alloy, is presented. A new experimental Alloy1 [8], a tempered variant Alloy $1 \mathrm{~T} 200\left(200^{\circ} \mathrm{C}\right.$ for $\left.1 \mathrm{~h}\right)$ and a commercial ballistic benchmark material were tested. The ballistic test indicates that Alloy 1 requires a minimum thickness of $7.5 \mathrm{~mm}$, while both the tempered variant and the benchmark steel seem to require $9 \mathrm{~mm}$ for STANAG Level 16 . SHPB tests show an apparent higher energy absorption capacity of Alloy 1 at strain-rates of 500-1000 1/s. Conventional tensile tests reveal the higher tensile strength of Alloy1 compared to Alloy1T200 and the benchmark alloy. Alloy1 T200 is more severely affected by triaxiality than the benchmark material, as shown in the notched tensile tests (results from Alloy1 could not be compared at this time). High temperature tensile tests show a clear delay in thermal softening of Alloy 1 up to $500^{\circ} \mathrm{C}$ if compared to the benchmark alloy.

\section{Acknowledgements}

The authors thank Dr. R. J. Mostert and Dr. P.H.G. Pistorius for all the informative discussions as well as T. Cloete of the Blast Impact Survivability Research Unit at the University of Cape Town for the help with speciment design and SHPB tests. 
The very kind help of Mr. J. Calitz of Eskom Research and Innovation Center in the tensile tests was exceedingly valuable. Partial funding by the NRF through the Technology and Human Resource for Industry Program is appreciated. Partial funding by the Damascus Armor Development Consortium through the Innovation Fund (currently the Technology Innovation Agency) Project no. T70044 is also appreciated. Finally, permission to publish from the Universtity of Pretoria and the Damascus Armor Development Consortium is acknowledged.

\section{References}

1. Protection Levels for Occupants of Logistic and Light Armoured Vehicles. STANAG 4569. 2004

2. Y. L. Bai. W. Johnson., Metals Tech. 9, (1982) 182190
3. J. A. Zukas. et al., Impact Dynamics (John Wiley Sons, New York 1982) 155

4. G. C. Corbeitt. S. R. Reid. W. Johnson., Int. J. Imact. Engng. 18, (1996) 141-230

5. W. Goldsmith., Int. J. Imact. Engng., 22, (1999) 95395

6. K. Maweja. W. E. Stumpf. Mat. Sci. Engng. A. 485, (2008) 140-153

7. H. Irdissi. K. Renard. D. Schryvers. P. J. Jacques., Scripta Materialia. 63, (2010) 961-964

8. High Ballistic Strength Martensitic Armour Steel Alloy. PCT/IB2010/052675

9. Ballistic test method for personal armour materials and combat clothing. STANAG 2920. 2003

10. H. Kolsky. Stress Wave in Solids (Oxford University Press, 1953) 87

11. G. T. Gray III., ASM International. (1999) 1-36 